Reviews

work a useful model.

Finn concludes the book by reflecting on a question often posed to her about her research, "But what were the major differences you found between Butte and Chuquicamata?" While there were differences, equally important were the commonalties. But most important, these two communities represent two sides of the same coin of multi-national capitalism. Our boundaries are permeable and our fates intertwined.

\title{
The Ecology of Practice: Studies of Food Crop Production in Sub-Saharan West Africa, A. Endre Nyerges, editor, Food and Nutrition in History and Anthropology series, Volume 12, Gordon and Breach Publishers; 1997. 259 p. : ill., maps
}

\section{Reviewed by Wendy Wilson Fall}

Dr. Wilson Fall is a social anthropologist living in Senegal, West Africa. A former instructor at the University of Maryland, Baltimore County, she now works in local NGO development and in the implementation of social surveys examining small holder farming.

\section{THEORY AND PRACTICE: NEW VIEWS IN ECOLOGICAL STUDIES}

Ecology of Practice: Studies of Food Crop Production in Sub-Saharan West Africa presents an example of the benefits of the "ecology of practice" approach. It gives a strong demonstration of the value of multi-dimensional analysis; in this case the confluence of the ecological perspective and anthropological process applied in the field context. The value of the volume is twofold: it gives examples of the rigorous application of a fairly new theoretical framework, and it provides examples which are well suited to comparison and thus allows the reader the advantage of being able to easily apply to one essay what was learned in another. The volume provides groundwork for further reflection and debate about the application of the "ecology of practice" to both the pursuit of knowledge as it pertains to understanding peasant production systems in the current era, and to pointed analysis for practicing, applied anthropologists whose input may have critical impact on the lives of people in communities such as described in the texts.

There are also major questions that arise after having completed the reading of such a collection in terms of a real apprehension of elements of a useful ecology of practice approach. These pertain to the significance of the "political economy variable" and to the possible role that related "hard" sciences such as agronomy, horticultural sciences, or soil sciences have to play in 
Reviews

refining the application of this framework. In the case of data drawn from west Africa, another recurring variable is the former importance or lack of importance of slave labor to the systems discussed, although this has perhaps not figured as importantly as it could have. These will be discussed after the following section, which presents certain subject themes that emerge throughout the collection, and their relation to the ecology of practice paradigm.

There are seven major themes in this collection of essays, which draw directly from field studies in West Africa. The data collected by the authors allows us to gain a coherent image of some of the major challenges and issues facing agricultural production and economic development in the region today: 1) the increasing cash needs and multiplying consumer habits of west African peasants, 2) the emerging observable results of earlier development policies (1970-1980) as they pertain to impact on farmer behavior and land use, and which need to be more often and more thoroughly studied, 3) the value of the concept of "biography of a resource" in analysis of competition for resources and competition of resources for food consumption versus cash needs, 4) the conundrum being faced by small holder farmers who seek to balance social value with cash values and find equilibrium in manipulating the two, 5) the variability of farmer response and the essential flexibility of farming adaptation in west Africa as a critical factor in food security in the region, 6) the increasing importance of manioc as a fall-back crop for nutritional and cash needs, and the gender specificities of its production on a north - south axis in the region and 7) the relation between the flexibility of west African modes of exploitation of natural resources and the specificities of the resource bases involved; in particular the intense use of ecological niches and the role of this use in the overall land and forestry use system.

Another message that comes across throughout the texts, though less consistently, is the problem of gender specificity in inter-cropping patterns and how this specificity relates to long term local ecological management goals. Melissa Leach and John Magistro, in particular, call our attention to the impending or already existing dangers of non-cyclical ecological changes which result from mono-cropping for cash income and shorter and shorter fallow periods. These two process also tend to be accompanied by a greater marginalization of women's inter-cropping systems or exploitation of moist low lands.

Special mention should be made of Paul Richards' excellent study of the conditions of rice research in Sierra Leone and its heritage of both genetic and political material that affected the rates of adoption of various rice strains. Richards does not hedge from explicitly documenting what he considers a double edged sword of international development assistance and encroaching hegemonic ideology regarding the direction from which miracles might emanate as well as the direction in which they should go. His work is an outstanding example of the value of the ecology of practice approach, for he presents the particular squarely in the context of the macroenvironment and major variables which are in play.

Thomas K. Park ("Indirass and the Political Ecology of Food") also goes beyond existing parameters by exploring the nuances of Islamic tradition and law in the context of the use of riverine and adjacent lands in southern and southeast Mauritania, and how such texts might be usefully applied in lieu of external, occidental models. In both cases, the specific nature of the problem examined is well described in relation to the larger contextual issues. This is a perspective that has been long due in anthropological work on production systems in Africa in general.

Also missing from most work on production systems in Africa in general, particularly from a land use and ecology perspective, has been the effect of the loss of control of labor through the ending of slavery. Texts in this volume begin to confront the subject of how the quest for labor in the West African context effects land use and cropping decisions. This work also clearly demonstrates the need for more reflection and research on how current social practices related to land use have evolved over the past century as coping mechanisms following the end of domestic slavery. One is particularly tempted to pose this question in reading about the Susu of Kilimi (Nyerges) in light of what we read in the same volume about the Mende. Could it be that the Susu were formerly more slave dependent? The same question is relevant in the report of the people of 


\section{Reviews}

Thiemping in northern Senegal (Magistro). One can't help wondering what these communities were doing before when certain machine technologies were not available, or certain geopolitical limits were not yet in place.

The "Ecology of Practice" approach goes beyond the theoretical gains of historical materialism and current anxieties about "subjectivity" by directly relating analysis in a chronological discussion that necessarily draws on outward as well as internal linkages whether they be economic, socio-cultural or purely political. If there is a danger there, it may be the temptation to become overly deterministic in following material causes for human's decision making, thus reducing the scope of the analysis and returning to what is essentially a transactional interpretation. The other danger in this attractive theoretical frontier is the danger to succumb to the mystification of one's own writing or mystification of the reader through over use of agronomic terms and concepts. In fact, this is a challenge to the approach that is significant. It implies that anthropologists take to heart the great need for their participation in examining problems of ecology without duplicating or re-discovering principles and assumptions that are the grist of the agronomist's mill. This is far more difficult than one would initially expect. It remains a just challenge in that agronomists or other scientists in related fields (hydraulic specialists, plant breeders, horticulturalists) depend on the social sciences to facilitate their entry past the farm gate; and to understand what happens after harvest. It is important therefore, that anthropologists concerned with ecology work closely with those of relevant sciences, take advantage of their literature, and, doing what we do best; understand their culture. An example might be that the fact that a small farm produces less volume; that it requires less labor is not a discovery in the world of the agronomist. What the agronomist depends on us to discover is the how and why of human behavior in that set of parameters.

This does not take us away from the Ecology of Practice but rather requires us to look more profoundly at the paradigm and work harder at its application. A "sociocentric approach to ecology" should bring us to better understandings of how "individual agency (practice, politics) links the exploitation of resources to technologies that are created and used for the realization of culturally important projects" (p. 2), as Nyerges points out in the introduction. This volume is in fact a valuable contribution to the important project of better analysis of humankind's relationship to nature and the problem of culture.

\section{The Anthropology of Infectious Disease: International Health Perspectives, edited by Marcia C. Inhorn and Peter J. Brown. Amsterdam: Gordon and Breach Publishers, 1997. xv, 495 pp.}

\section{Reviewed by Barbara Herr Harthorn, Center for Global Studies/Institute for Social, Behavioral, and Economic Research, University of California at Santa Barbara.}

The Anthropology of Infectious Disease represents the first systematic collection of work exploring anthropologists' unique contribution to the international study of infectious disease. It is an important and groundbreaking work that will prove a crucial resource and baseline for future work by anthropologists and others as well. The "springboard" for the book was a session of the 